\title{
The System Innovation of Regional Public Management: Dilemmas and Breakthroughs
}

\author{
Yang Yanhong \\ School of Public Management, Yunnan University of Finance and Economics, P. R. China \\ (Email:yangzi30@126.com)
}

\begin{abstract}
With the rapid development of global economic integration and the process of modernization of China, the regional public administration issues are constantly highlighted. The regional public administration has become the inevitable trend for adapting to the developing times. This essay is based on the analysis of the difficulties in the regional public administration of China and proposes effective ways to break the bottleneck of the system innovation of regional public administration.
\end{abstract}

Key Words: Dilemmas; breakthroughs, regional public administration

\section{Introduction}

In the historical process of China's reformation and opening up more than 30 years, the economic patterns have changed constantly, brought with the reformation of government administration model. The problem of "governance failure" in the "administrative region"is highlighted which results from the rigid administration division. A more effective model of "regional public administration" came to break the traditionalmodel of "administrative region" governance, and it continued to seek the innovative system to resolve various public issues of regional development.

\section{The innovation analysis of regional public} \section{administration system}

The regional public administration is based on the cooperation of regional governmental organization and non-governmental organization, and to solve the public issues of specific region, to achieve regional public interest and modern administrative social activities. [1] Compared to the organizational form through the bureaucracy system, and the traditional administration, it is more effective to solve the crossregional public issues by regional public administration. The regional public administration system achieves the preliminary cooperation in many aspects, such as strengthening the regional unified planning, the reformation of administrative division, the planning of metropolitan circle, the interaction and cooperation between local governments, the negotiationbetween departments and so on. But in the process of old system switching to new system, it is inevitable to have numerous and complicated motivations and the factors influencing institutional innovation also emerge in endlessly.

On the one hand,with the economic globalization, regional management, social informationization and networking of organization of the complex socioeconomic conditions, with the deepening cooperation of international and domestic regions,such as China ASEAN free trade area, the greater Mekong subregional cooperation, pan-pearl river delta regional cooperation, Shanghai free trade zone, BCIM economic corridors, China-Pakistan economic corridor, the regional economic integration development environment has been gradually formed, followed by a large number of regional public problems. On the other hand, with the rapid increasing process of China's industrialization and urbanization more than twenty years, the present situation is the serious unbalanced 
development.There is a huge gap exist in thelevel of modernization and development in space area. It is inevitable that it will aggravate the problem of regional public management. China'sregional economic cooperation and development should integrate with international environment to realize the actual meaning of modernization development. If we want tobreak thebottleneck of the unbalanced development, we must carry out development and innovation in the governance mode of regional public management.

3.The difficulties of system innovation of regional public management in China

3.1 The shackles of administrative region has not been broken

Due to the special background of history and system, the economy function is still a very prominent feature at all levels of administrative region in China nowadays. The desire of interfering in economy which exists in the local government is still very strong at all levels. In order to maximize their own interests, they makedifferent local protection policy; it results in the competition over cooperation between local governments. This behavior consciousness is like an invisible wall, to generate the rigid constraintson the horizontal linkages of regional economy, the cross-regional flows are severely hampered, it is difficult to achievesystem innovation of regional public management.

\subsection{The legal protection of regionalcooperation is not yet perfect}

Institutional innovation is based on the existing laws and rules, if the content of the existing laws or rules incompatible with innovation, it will directly affect the time of system innovation.At present, the concrete rules and regulations of our country's constitutioninvolved in the cooperation of regional city are almost blank.In the condition of the property rightswhich is unclear, the responsibility is not definite, the legal provisionsareinadequate,so the cooperation between the governments is "rules of man" greater than "rule of law", the process of cooperation and arbitrary manner, the region is still around the GDP as a measurement of economic development. Therefore, it is difficult to get institutional innovation in the further implementation of the legalization of space.

\subsection{Single subject in theregional management}

At present, there is a single body in China's regional public management,the affairs of regional cooperation is mainly dominated by the central government and local governments, and the participation of enterprises, individuals, groups and non-governmental organizations is lacking, the coordinating organization led by government is difficult to play a substantive role. Admittedly, the governmentas the representative of the administrative public interest is unquestioned as dominant position of authority. However, if it lacksparticipation of social forces, the government will not provide regional public services effectivelyby use of the unity and the cooperation of social forces, the institutional arrangements to changes can only stay at the policy level.

\subsection{Lack of regional human capital}

With the continuous development of regional economic integration, the demand for all kinds of talent on the quality and quantity is put forward on higher requirements. But in the practice of the regional public management, the government tends to focus on regional hard indicators of growth, while ignoring the introduction and development of talent. Many factors greatly reducing the overall vitality of regional innovation, for example, the shortage of 
regional talent, the talent flow is impeded, integration mechanisms of regional talentare inadequate and others. The system innovation of regional public management will be stagnant due to lack of creativity.

\section{Breakthroughs of system innovation of regional public management}

\subsection{Establishingregional government win-win} mechanisms

At present, thelocal governments of various levels in Chinaare still under the influence of traditional administrative system and often overlook the governance and cooperation of regional public management affairs for the sake of their own interests. Therefore, it is particularly necessary to establish regional win-win mechanisms recognized by various stakeholders. The first one is the mechanism of interests sharing, namely local governments at various levels realize the transfer and reasonable distribution of interests among different regions by various methods and means on the basis of an overall regional development planning. The second one is the mechanism of interest compensation, namely when local short-term interests are incongruous with the development of the entire region's interests, regional government's cooperative agencies provide interest compensation by effective means on the frame foundation of institutional consensus to enhance various local governments' initiative and enthusiasm in participating in regional public management.

\subsection{Promoting the Course of Legal Construction}

Governance by law is an indispensable factor for the social reformation in contemporary China. To definite the responsibility and authority of various local governments by law, it can promote the institutional innovation towards a rationalized direction. Laws and regulations are effective guarantee for local governments to cooperate, and formulating the laws and regulations regarding regional cooperation can ensure the authoritativeness of regional policy and the continuity of cooperation. It is necessary to perfect the laws and regulations concerning the cooperation in regional public management as soon as possible and to normalize the behaviors of local government cooperation by means of law, thus creating a favorable institutional environment for institutional innovation.

\subsection{Cultivating and developingsocial forces}

Under the dual impact of global economic integration and social transformation, the institutional innovation of China's regional public management needs the mutual participation of multiple social capital forces such as governments, profit organizations, non-profit organizations and non-governmental organizations. Therefore, it is necessary to establish multidimensional and multilevel institutionalized organizations among the central government, local governments and civil society. On one side, strengthening the authoritativeness of regional coordinators is set up by central and local governments so that regional problems can be effectively communicated and coordinated by centralized and powerful organizations. On the other hand, to cultivate social capitals which benefit for the construction of regional government and to build up an interactive governance model for modern serviceoriented local governments and civil society.

\subsection{Strengthening the integrationconstruction of regional talents}

The integration of regional talent development is a core motivation for promoting the institutional innovation of regional public management. In order 
to realize the integration of regional talents, government must have a clear understanding of the role of talents in regional public management and of the strategic objective of the integration of talent development, and deeply study and formulate the policies and regulations relating to talent integration to further create an environment favorable for the development of various talents. Only in this way can the vitality and creativity of talents be motivated, thus providing a powerful intellectual support for the realization of regional institutional innovation.

\section{Conclusion}

The competition and development under the tendency of economic globalization is actually the competition and development among regions. Regional public management can not only integrate the resources inside government system, but gather the market and social resources outside government system. It can realize effective governance and is a kind of inevitable development tendency. Under the current environment, it is advisable to gradually solve the imbalance and instability problems in China's regional public management and further strengthen the institutional innovation of regional public management. We have reasons to believe that with the advancement of economic integration, the system innovation of regional public management will become effective respond and inevitable choice to government in the face of regional economic integration. This is a big change of traditional governance model of mainstreamgovernment.

\section{References}

(1). The Introduction of Regional Public Management. (2006).Beijing: China Social Sciences Press
(2). Yang Aiping, Chen Ruilian. (2004). From Administrative Region to Regional Public administration.Jiangxi social Sciences, 11

\{3). Jin Taijun,Sheng Chengcheng. (2007). The Research On The Internal Mechanism Of The Regional Public Administration System Innovation Dilemma. Beijing: China Public Administration

(4). Wang Dianli. (2009). Regional Public Management System And Mechanism Innovation Analysis. Beijing Administrative College Journal, (5)

(5). Chen Ruilian. (2005). Regional Public Management System Innovation. Journal of Sun Yat-Sen, (5)

(6). Maurice Schiff\&L.Alan Winters. (2005). Regional Integration And Development.Beijing: China Financial And Economic Publishing Press

(7). Zhang Jingen. (2010). Regional Public Management System Innovation Analysis: The Pearl River Delta As An Example. Political Science Research, 3

(8). Chen Ruilian,Kong Kai. (2009). The Development Of China's Regional Public Management Research And Foresight. Academic Research, 1

[9]. Lv Jun. (2011). Regional Public Management System Innovation. Management, 10 